\title{
Efficacy of prophylactic epidural ketamine for reducing shivering in patients undergoing caesarean section with combined spinal-epidural anesthesia
}

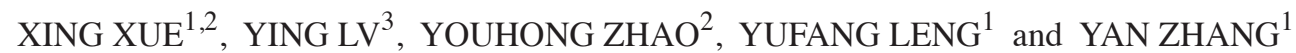 \\ ${ }^{1}$ Department of Anesthesiology, The First Hospital of Lanzhou University, Lanzhou, Gansu 730000; ${ }^{2}$ Department of \\ Anesthesiology, Gansu Provincial Maternity and Child-Care Hospital, Lanzhou, Gansu 730050; ${ }^{3}$ School of Environmental and \\ Municipal Engineering, Lanzhou Jiaotong University, Lanzhou, Gansu 730070, P.R. China
}

Received September 22, 2017; Accepted February 23, 2018

DOI: 10.3892/br.2018.1072

\begin{abstract}
Intravenous ketamine is known to inhibit postoperative shivering; however, at present, there has been little research on whether this effect may be achieved with epidural application. The aim of the present study was to evaluate the efficacy and safety of epidural ketamine as a prophylactic agent to prevent shivering in patients undergoing caesarean section during combined spinal-epidural anesthesia. A prospective, randomized, double-blind study was performed. A total of 60 patients who were undergoing elective caesarean section under combined spinal-epidural anesthesia and had an American Society of Anesthesiologists physical status of I or II were recruited. Patients were randomly allocated to group $\mathrm{S}$ (epidural administration of normal saline; $\mathrm{n}=30$ ) or group $\mathrm{K}$ (epidural ketamine $0.5 \mathrm{mg} / \mathrm{kg}$; $\mathrm{n}=30$ ). An investigator, blinded to the treatment groups, graded postoperative shivering using a 4-point scale and postoperative sedation on a 5-point scale. Operative time, hemodynamic changes and side effects, including hypotension, bradycardia, nausea and hallucinations, were recorded. The results demonstrated that patients' characteristics were not significantly different between groups. Heart rate, peripheral capillary oxygen saturation $\left(\mathrm{SpO}_{2}\right)$ values and Apgar scores at 1 and 5 min also did not differ significantly between groups. The incidence and severity of shivering in group $\mathrm{K}$ was significantly reduced compared with group $\mathrm{S}(\mathrm{P}<0.05)$. The mean arterial pressure (MAP) was significantly different in groups $\mathrm{S}$ and $\mathrm{K}$ compared with baseline values at 10,30 and $60 \mathrm{~min}(\mathrm{P}<0.05)$. Furthermore, MAP values at 10, 30 and 60 min were significantly higher in group $\mathrm{K}$ compared with in group $\mathrm{S}(\mathrm{P}<0.05)$. The results
\end{abstract}

Correspondence to: Professor Yufang Leng, Department of Anesthesiology, The First Hospital of Lanzhou University, 1 Donggang West Road, Chengguan, Lanzhou, Gansu 730000, P.R. China

E-mail: lengyf@lzu.edu.cn

Key words: epidural, ketamine, complications, shivering, caesarean section of the present study suggest that epidural administration of prophylactic low-dose ketamine may be an effective strategy for preventing postoperative shivering.

\section{Introduction}

Combined spinal-epidural anesthesia (CSE) is a popular and well-accepted technique for caesarean section (1). Shivering is one of the most frequent complications associated with spinal or epidural anesthesia, with an occurrence rate of $45-85 \%$ (2). Neuraxial techniques may obtund skin afferents and decrease the vasoconstriction threshold even beyond the level of sensory block, thereby reducing a patient's ability to maintain their core body temperature (poikilothermia), which may lead to shivering $(3,4)$. However, the exact mechanism of this is not clear. Shivering is uncomfortable for affected patients and may interfere with monitoring of the electrocardiogram, blood pressure and oxygen saturation (5). It may also increase oxygen consumption, lactic acidosis and carbon dioxide production, as well as causing distress to parturients with a low cardiac pulmonary reserve and a high metabolism $(3,6,7)$. Thus, prevention and treatment of shivering is an important aspect of patient care during CSE, resulting in better postoperative outcomes and a reduced incidence of post-surgical complications (8).

At present, a number of pharmacological methods are used to treat shivering (9). Many medications have been investigated for their ability to control postoperative shivering, including meperidine and tramadol (10). However, these medications may have adverse effects on the baby if administered to parturients prior to delivery $(9,11)$.

Ketamine, which is a noncompetitive antagonist of $\mathrm{N}$-methyl-D-aspartic acid (NMDA) receptors, serves a role in thermoregulation on various levels (12). NMDA receptors modulate the noradrenergic and serotonergic neurons in the locus coeruleus; consequently, NMDA receptors in the dorsal horn of the spinal cord facilitate the transmission of ascending nociceptive stimuli (12). A previous study reported that intravenous ketamine is able to inhibit postoperative shivering (13); however, whether epidural application has the same effect is yet to be established. The aim of the present study was to investigate whether $0.5 \mathrm{mg} / \mathrm{kg}$ of epidurally administered ketamine 
affects the incidence and severity of shivering and to evaluate the efficacy and safety of epidural ketamine as a prophylactic agent for the prevention of shivering in patients undergoing caesarean section during CSE.

\section{Materials and methods}

Patients and ethics. The present study was approved by the Ethics Committee of Gansu Provincial Maternity and Child-Care Hospital (Lanzhou, China). A prospective, randomized, double-blind study was performed and prior written informed consent was obtained from all patients. A previous clinical study reported the incidence of shivering in caesarean section as $55 \%$ (10). The sample size required to detect a $40 \%$ reduction was a minimum of 28 patients in each group; therefore, 30 patients were included in each group in the present study. Thus, a total of 60 female patients ( 22 to 41 years of age) with an American Society of Anesthesiologists (ASA) physical status of I-II and who were scheduled for elective caesarean section under CSE were recruited for the current trial. Patients were randomly divided into two groups (group $\mathrm{S}$ and group $\mathrm{K}$; $\mathrm{n}=30$ per group) using a computer-generated code. Exclusion criteria were as follows: History of severe cardiovascular complications, preoperative temperature $>38^{\circ} \mathrm{C}$ or $<35^{\circ} \mathrm{C}$, any contraindications to regional anesthesia, ketamine allergy, preeclampsia, diabetes mellitus, significant peripartum hemorrhage or the existence of an absolute or relative contraindication for the application of the epidural technique, including neuromuscular disease, bleeding tendency or local skin infection in the lumbar region. A previous study (14) reported that intraoperative shivering is not associated with intraoperative temperature. The intraoperative room temperature and the temperature of the infusion liquid were controlled and, although the intraoperative temperature was monitored during the present study, it was not included as a detection index. If the intraoperative anesthetic effect was insufficient or patients reported pain during surgery, 50-100 $\mu \mathrm{g}$ fentanyl (Yichang Renfu Pharmaceutical Co., Ltd., Yichang, China; production batch no. 100404) was administered.

Surgical procedure and treatments. The temperature of the operating room was maintained at $23-25^{\circ} \mathrm{C}$, with a humidity of 55-65\%. Lactated Ringer's solution (Sichuan Kelun Pharmaceutical Co., Ltd., Chengdu, China; production batch no. B12122104) was preheated to $37^{\circ} \mathrm{C}$ in a warmed cabinet and $10 \mathrm{ml} / \mathrm{kg}$ was administered intravenously over $30 \mathrm{~min}$. All parturients were placed under standard monitoring.

CSE was performed in the left lateral decubitus position at the L3-L4 lumbar vertebral interspace, with $10 \mathrm{mg}$ $0.5 \%$ hyperbaric bupivacaine by a needle-through-needle technique (27G/18G spinal/epidural needle; Tuoren Medical Co., Ltd., Xinxiang, China). The spinal needle was removed and the epidural catheter was inserted $4 \mathrm{~cm}$ from the end of the needle into the epidural space and secured aseptically. All treatments were administered by an anesthesiologist who was blinded to study group allocation. In group S, all patients received $3 \mathrm{ml}$ saline by epidural bolus. In group $\mathrm{K}$, all patients received $3 \mathrm{ml}$ ketamine $(0.5 \mathrm{mg} / \mathrm{kg}$; Fujian Gutian Pharmaceutical Co., Ltd., Gutian, China; production batch no. 1303032) by epidural bolus. Parturient were subsequently placed in a supine position with a left lateral tilt $\left(15^{\circ}\right)$.
Monitoring. Sensory and motor assessments were performed at 1-min intervals using pinprick testing and the modified Bromage score (15), respectively. Surgery began when adequate anesthesia to the T6 dermatome was achieved. The time of ketamine/saline administration and the duration of surgery (from initial skin incision to the last stitch) were recorded, as were hemodynamic changes and the amount of irrigation fluid used during the procedure. Side effects, including hypotension, amnesia, nausea and hallucinations, were also recorded. The Apgar scale at 1 and 5 min after birth of baby was recorded (16). All hypotensive episodes were treated by crystalloid infusion if necessary, with intravenous ephedrine (5-15 mg; Northeast Pharmaceutical Group Co., Ltd., Shengyang, China; production batch no. 131102-1).

Shivering grading. Shivering was graded with a scale similar to that validated by Crossley and Mahajan (14). Grades were as follows: 0, no shivering; 1, piloerection or peripheral vasoconstriction with no visible shivering; 2 , muscular activity in 1 muscle group; 3, muscular activity in $>1$ muscle group, but not generalized shivering; and 4 , shivering involving the whole body. When shivering grade was $\geq 3$, patients were treated with $25 \mathrm{mg}$ intravenous meperidine (Yichang Renfu Pharmaceutical Co., Ltd.; production batch no. 110406).

Sedation grading. Hallucination, as a side effect, was defined as a false sensory experience in which the patient reported that they saw, heard, smelled, tasted, or felt something that was nonexistent. The attending anesthesiologist also assessed the degree of sedation on a 5-point scale as follows: 1 , fully awake and oriented; 2, drowsy; 3 , eyes closed but rousable to command; 4, eyes closed but rousable to mild physical stimulation; and 5, eyes closed but unarousable to mild physical stimulation (17). All data were recorded pre-operatively and at 10, 30 and $60 \mathrm{~min}$ following anesthesia.

Statistical analysis. A power analysis was performed using a power threshold of $90 \%$ and an $\alpha$-value of 0.05 . The Power and Sample Size statistics program (PS version 3.0.43; Vanderbilt University, Nashville, TN, USA) was used for power analysis. Data are presented as the mean \pm standard deviation for continuous data and frequency for non-parametric data. Differences between demographic anesthetic and surgical characteristics of patients were assessed using an independent t-test. Fisher's exact test was used to analyze categorical variables. Differences in heart rate, peripheral capillary oxygen saturation $\left(\mathrm{SpO}_{2}\right)$ and mean arterial pressure (MAP) at different time-points were assessed using repeated measures analysis of variance with Dunnett's test. SPSS 18.0 (SPSS, Inc., Chicago, IL, USA) was utilized to perform the tests and $\mathrm{P}<0.05$ was considered to indicate a statistically significant difference.

\section{Results}

Patient characteristics. A total of 60 parturients were enrolled in the present study and randomized into the two groups $(n=30$; Fig. 1). No significant differences in patient characteristics, including age, body mass index, gestational week and operation duration were observed between groups (Table I). 


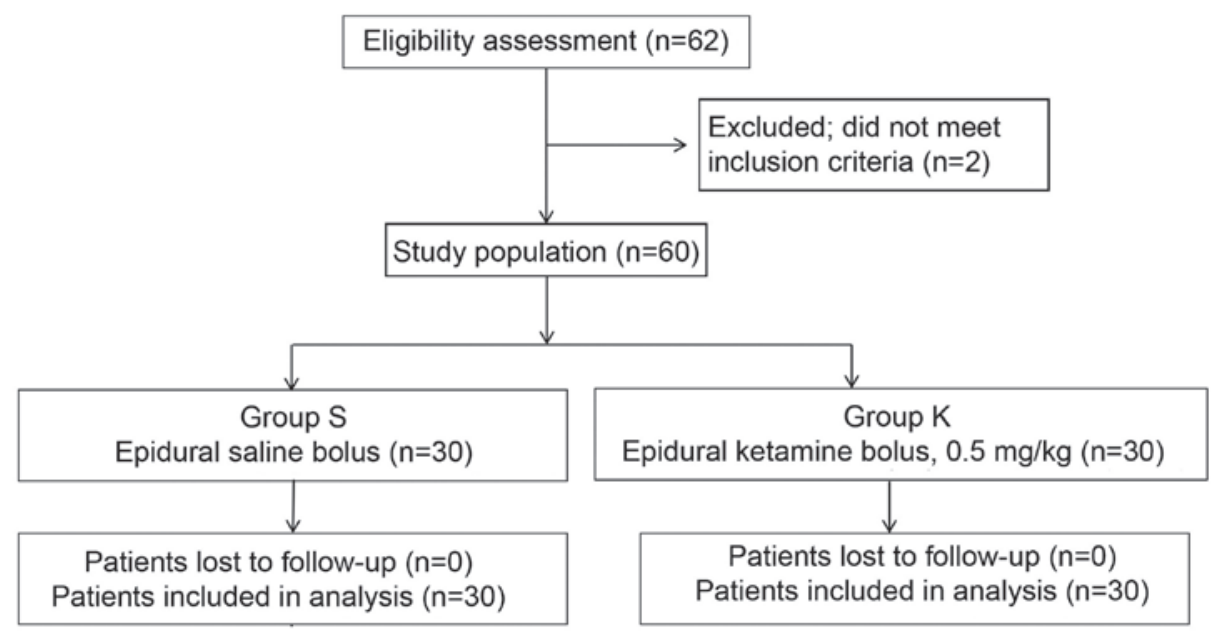

Figure 1. Study flowchart.

Table I. Patient characteristics.

\begin{tabular}{lcc}
\hline Patient characteristics & $\begin{array}{c}\text { Group S } \\
(\mathrm{n}=30)\end{array}$ & $\begin{array}{c}\text { Group K } \\
(\mathrm{n}=30)\end{array}$ \\
\hline Age (years) & $27.8 \pm 6.3$ & $28.1 \pm 5.7$ \\
Body mass index $\left(\mathrm{kg} / \mathrm{m}^{2}\right)$ & $27.8 \pm 3.5$ & $27.6 \pm 3.3$ \\
Gestational age (weeks) & $39.3 \pm 1.0$ & $38.9 \pm 1.1$ \\
Operation duration $(\mathrm{min})$ & $59.3 \pm 13.6$ & $60.0 \pm 13.7$ \\
Heart rate $(\mathrm{bpm})$ & $94.3 \pm 11.5$ & $91.9 \pm 15.3$ \\
SPO $(\%)$ & $100 \pm 0$ & $100 \pm 0$ \\
Apgar score & & \\
5 min & $8.8 \pm 0.9$ & $8.7 \pm 1.2$ \\
10 min & $10 \pm 0.0$ & $10 \pm 0.0$ \\
\hline
\end{tabular}

Data are presented as the mean \pm standard deviation. $\mathrm{SpO}_{2}$, peripheral capillary oxygen saturation.

No significant differences were observed in the Apgar scores at 1 and 5 between groups (Table I). Furthermore, no significant differences in heart rate and $\mathrm{SpO}_{2}$ values between groups were observed at any time (Table I). However, MAP in groups $\mathrm{S}$ and $\mathrm{K}$ were significantly reduced compared with the baseline at 10, 30 and $60 \mathrm{~min}(\mathrm{P}<0.05$; Fig. 2). In addition, MAP was significantly lower in group $\mathrm{S}$ compared with group $\mathrm{K}$ at 10, 30 and $60 \mathrm{~min}(\mathrm{P}<0.05$; Fig. 2).

Shivering grade. At $30 \mathrm{~min}$, the incidence and severity of shivering in group $\mathrm{K}$ were significantly lower compared with group $\mathrm{S}$ (Table II). At $10 \mathrm{~min}, 2$ patients in group $\mathrm{S}$ were shivering, compared with 1 patient in group $\mathrm{K}$. At $30 \mathrm{~min}, 10$ patients experienced shivering in group $\mathrm{S}$, of whom 2 suffered grade 3 and 2 suffered grade 4 shivering, whereas only 2 patients experienced shivering in group $\mathrm{K}$, both of grade 1. At $60 \mathrm{~min}, 3$ patients experienced shivering in group $\mathrm{S}$ (of whom 2 suffered grade 3 shivering), whereas only 1 patient experienced shivering (grade 2 ) in group $\mathrm{K}$. Following treatment with intravenous meperidine $(25 \mathrm{mg})$, shivering ceased in all patients.

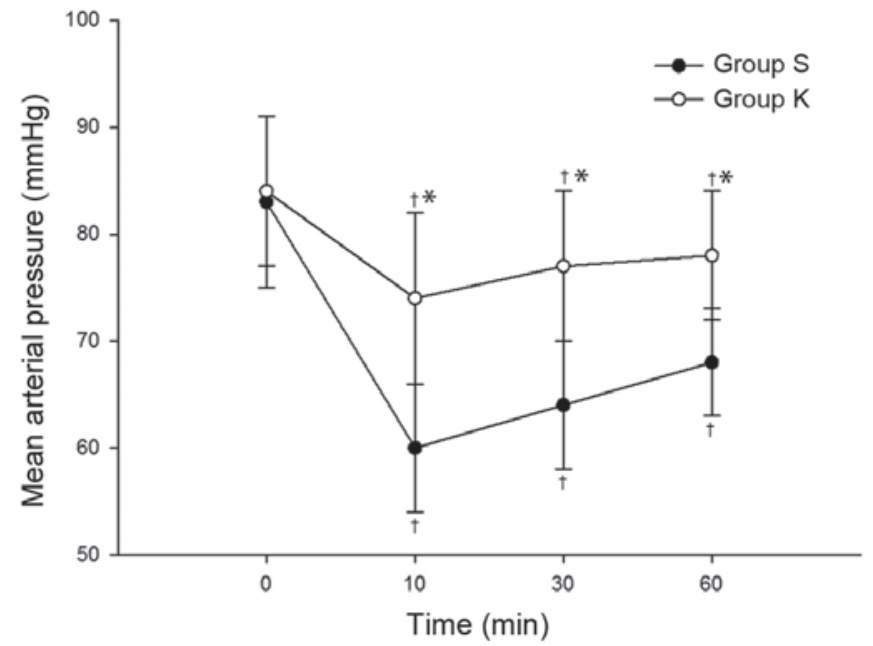

Figure 2. Change in mean arterial pressure over time. Data are presented as the mean \pm standard deviation. ${ }^{*} \mathrm{P}<0.05$ vs. group $\mathrm{S} .{ }^{\dagger} \mathrm{P}<0.05$ vs. baseline.

Sedation grade. Sedation was one of the side effects of ketamine. In group K, 15 patients exhibited grade 2 sedation and 2 patients exhibited grade 3 sedation at the $10 \mathrm{~min}$ time-point. At $30 \mathrm{~min}, 5$ patients experienced grade 2 sedation and at $60 \mathrm{~min}, 2$ patients experienced grade 2 sedation. No patients experienced sedation at grade 4 or 5 (Table III). In group S, patients did not use any sedative drugs, and were all in a natural awakened state.

Incidence of side effects. The frequency of nausea and hypotension (systolic pressure, $<90 \mathrm{mmHg}$ ) was significantly higher in group $\mathrm{S}$ compared with group $\mathrm{K}$, as was the number of patients who received ephedrine $(\mathrm{P}<0.05$; Table IV). None of the common side effects of ketamine, including nystagmus, hallucinations and amnesia, were observed (Table IV).

\section{Discussion}

Shivering is a common and uncomfortable side effect associated with neuraxial anesthesia. Neuraxial techniques may block the activity of the sympathetic nervous system and 
Table II. Shivering grade at different time-points.

\begin{tabular}{|c|c|c|c|c|c|c|c|c|}
\hline \multirow[b]{2}{*}{ Shivering grade } & \multicolumn{4}{|c|}{ Group $S(n=30)$} & \multicolumn{4}{|c|}{ Group K $(\mathrm{n}=30)$} \\
\hline & Pre-operation & $10 \mathrm{~min}$ & $30 \mathrm{~min}$ & $60 \mathrm{~min}$ & Pre-operation & $10 \mathrm{~min}$ & $30 \mathrm{~min}$ & $60 \mathrm{~min}$ \\
\hline 0 & 30 & 28 & 20 & 27 & 30 & 29 & $28^{\mathrm{a}}$ & 29 \\
\hline 1 & 0 & 0 & 5 & 0 & 0 & 0 & 2 & 0 \\
\hline 2 & 0 & 2 & 1 & 1 & 0 & 1 & 0 & 1 \\
\hline 3 & 0 & 0 & 2 & 2 & 0 & 0 & 0 & 0 \\
\hline 4 & 0 & 0 & 2 & 0 & 0 & 0 & 0 & 0 \\
\hline
\end{tabular}

${ }^{\mathrm{a}} \mathrm{P}<0.05$ vs. group $\mathrm{S}$ at the same time-point.

Table III. Sedation grade in group K $(n=30)$.

\begin{tabular}{lrrrr}
\hline Sedation grade & Pre-operation & 10 min & 30 min & 60 min \\
\hline 1 & 30 & 13 & 25 & 28 \\
2 & 0 & 15 & 5 & 2 \\
3 & 0 & 2 & 0 & 0 \\
4 & 0 & 0 & 0 & 0 \\
5 & 0 & 0 & 0 & 0 \\
\hline
\end{tabular}

Table IV. Incidence of side effects.

\begin{tabular}{lcc}
\hline Symptom & Group S $(\mathrm{n}=30)$ & Group K $(\mathrm{n}=30)$ \\
\hline Nausea & 12 & $2^{\mathrm{a}}$ \\
Hypotension & 10 & $3^{\mathrm{a}}$ \\
Nystagmus & 0 & 0 \\
Hallucinations & 0 & 0 \\
Amnesia & 0 & 0 \\
Ephedrine & 6 & $2^{\mathrm{a}}$ \\
\hline
\end{tabular}

${ }^{\mathrm{a}} \mathrm{P}<0.05$ vs. group $\mathrm{S}$.

reduce a patient's ability to regulate body temperature (18). Additionally, it may. inhibit thermoregulatory control centrally and lead to internal redistribution of heat from the core to the periphery $(19,20)$. In addition, the release of amniotic fluid from the mother's body may lead to heat loss (21). Collectively, all of these factors may increase the incidence of shivering in parturients.

Shivering during and following caesarean section increases oxygen consumption and the burden on the heart and lungs, as well as reducing hepatorenal blood flow, influencing uterine contractions and extending the anesthesia recovery time $(2,11,22)$. Therefore, intraoperative and postoperative prevention of shivering in patients receiving epidural anesthesia is of important clinical significance (23). Although shivering is a protective mechanism when the body is subjected to low temperatures, there is no definite linear relationship that exists between body temperature and the occurrence of shivering during CSE; shivering may also be observed in normothermic patients under spinal anesthesia (24), suggesting that mechanisms other than heat loss and subsequent decrease in core temperature contribute to the development of shivering. These mechanisms may include uninhibited spinal reflexes, postoperative pain, decreased sympathetic activity, pyrogen release, adrenal suppression and respiratory alkalosis (25). Shivering may therefore be considered both thermogenic and non-thermogenic $(14,23)$. As such, a variety of measures are widely used to prevent postoperative shivering $(22,26,27)$.

A number of pharmacological methods for inhibiting shivering have been reported $(28,29)$. Numerous pharmacological interventions have been proposed for the treatment of postoperative shivering, however the ideal treatment has not yet been established (9). Meperidine has been reported to be one of the most effective drugs used to treat post-anesthetic shivering $(30,31)$. In the present study, $25 \mathrm{mg}$ meperidine was intravenously administered if the severity of shivering was above grade 2 . The side effects of intravenous meperidine, including nausea, vomiting, pruritus, hypotension, bronchospasm, bradycardia and respiratory insufficiency, have been reported to be dose-related (32) and may limit the application of this agent, particularly in parturients.

Ketamine was first described in the literature in 1965 (33). Although it was originally noted for its anesthetic effects, ketamine has numerous pharmacological properties, including the capacity to block amine uptake in the descending inhibitory monoaminergic pain pathways, interactions with muscarinic receptors, local anesthetic action and the ability to act as a kappa opioid agonist (34). Previous studies have reported that ketamine administered via continuous intravenous infusion enhances the analgesic effect of morphine even after the effect of ketamine had ceased in obstetric patients, while also being safe for both mother and baby and not affecting breastfeeding $(35,36)$.

Intravenous administration of ketamine has been reported to effectively prevent and treat shivering in patients undergoing cesarean section. However, there has been little research conducted to establish whether ketamine administered epidurally may produce the same effect. The present study was designed to determine the effectiveness of epidural ketamine for the prevention of shivering in patients undergoing caesarean delivery with CSE. The study was designed to standardize the possible confounding factors while reflecting normal practice 
in our institution. To facilitate this, the temperature of the operating room was maintained at $22-24^{\circ} \mathrm{C}$ and the intravenous and irrigation solutions were also maintained at $37^{\circ} \mathrm{C}$ during surgery.

Prophylactic ketamine was administered epidurally with the aim of reducing postoperative shivering. Following spinal anesthesia, the incidence and severity of shivering in group $\mathrm{K}$ was significantly reduced compared with group S. Small fluctuations in MAP were observed, with MAP remaining more stable in group $\mathrm{S}$ compared with group K. Ketamine causes sympathetic stimulation and vasoconstriction (37) and may ameliorate the drop in blood pressure caused by spinal anesthesia. The incidence of nausea in group $\mathrm{K}$ was lower compared with group S, possibly due to fluctuations in MAP, as hypotension may cause brain stem hypoperfusion, thus triggering nausea and vomiting (38).

Ketamine may decrease the core-to-peripheral redistribution of heat by direct central sympathetic stimulation and inhibition of norepinephrine uptake into the postganglionic sympathetic nerve endings (12). However, the exact mechanism of ketamine remains unclear. Low-dose ketamine, as previously defined in the literature (37), was used in the present study as this dose has previously been used effectively to treat post-operative shivering (39). The results of the present study demonstrated that low-dose ketamine reduced shivering as well as the incidence of adverse effects. No hallucinations or delirium, which are well-known side effects of ketamine (37), were observed in any of the patient. Furthermore, none of the patients in group $\mathrm{K}$ had sedation scores $>3$ or reported amnesia. However, sedation is actually beneficial during surgery under spinal anesthesia, as it may reduce anxiety and improve patient comfort and cooperation (40).

In summary, the results of the present study suggest that prophylactic epidural administration of low-dose ketamine is able to reduce the incidence and severity of shivering in patients undergoing caesarean section with CSE. However, the present study focused on the occurrence and prevention of intraoperative shivering and only investigated single-dose ketamine. Future studies should investigate the potential of ketamine to reduce postoperative shivering in the future and seek to elucidate the optimal dose.

\section{Acknowledgements}

Not applicable.

\section{Funding}

This study was supported by the Natural Science Foundation of Gansu Province of China (grant no. 145RJZA171).

\section{Availability of data and materials}

The datasets used and/or analyzed during the current study are available from the corresponding author on reasonable request.

\section{Authors' contributions}

XX, YLv and YLe conceived and designed the study. YoZ and YaZ performed the majority of the experimental procedures.
YLv analyzed the data. XX wrote the paper. All authors read and approved the final manuscript.

\section{Ethics approval and consent to participate}

The present study was approved by the Ethics Committee of Gansu Provincial Maternity and Child-Care Hospital (Lanzhou, China) and obtained informed consent from all participants.

\section{Consent for publication}

Not applicable.

\section{Competing interests}

All authors declare that they have no competing interests.

\section{References}

1. Salman C, Kayacan N, Ertuğrul F, Bıgat Z and Karslı B: Combined spinal-epidural anesthesia with epidural volume extension causes a higher level of block than single-shot spinal anesthesia. Braz J Anesthesiol 63: 267-272, 2013.

2. Crossley AWA, Mcvey FK and Cartwright DP: Perioperative shivering. Lancet 338: 1026, 1991.

3. Shakya S, Chaturvedi A and Sah BP: Prophylactic low dose ketamine and ondansetron for prevention of shivering during spinal anaesthesia. J Anaesthesiol Clin Pharmacol 26: 465-469, 2010.

4. Sessler DI: Temperature monitoring and perioperative thermoregulation. Anesthesiology 109: 318-338, 2008

5. Badawy AA and Mokhtar AM: The role of ondansetron in prevention of post-spinal shivering (PSS) in obstetric patients: A double-blind randomized controlled trial. Egypt J Anaesth 33, 29-33, 2017.

6. Kose EA, Dal D, Akinci SB, Saricaoglu F and Aypar U: The efficacy of ketamine for the treatment of postoperative shivering. Anesth Analg 106: 120-122, 2008.

7. Zahra FA, Abudallah HM, Shabana RI, Abdulmageed WM, Abdulrazik SI and Nassar AM: Intramuscular ketamine for prevention of postanesthesia shivering in children. Saudi Med J 29: 1255-1259, 2008.

8. Crowley LJ and Buggy DJ: Shivering and neuraxial anesthesia. Reg Anesth Pain Med 33: 241-252, 2008.

9. Kranke P, Eberhart LH, Roewer N and Tramèr MR: Pharmacological treatment of postoperative shivering: A quantitative systematic review of randomized controlled trials. Anesth Analg 94: 453-460, 2002.

10. de Figueiredo Locks G: Incidence of shivering after cesarean section under spinal anesthesia with or without intrathecal sufentanil: A randomized study. Rev Bras Anestesiol 62: 676-684, 2012.

11. Tsai YC and Chu KS: A comparison of tramadol, amitriptyline, and meperidine for postepidural anesthetic shivering in parturients. Anesth Analg 93: 1288-1292, 2001.

12. Dal D, Kose A, Honca M, Akinci SB, Basgul E and Aypar U: Efficacy of prophylactic ketamine in preventing postoperative shivering. Br J Anaesth 95: 189-192, 2005.

13. Kose EA, Honca M, Dal D, Akinci SB and Aypar U: Prophylactic ketamine to prevent shivering in parturients undergoing Cesarean delivery during spinal anesthesia. J Clin Anesth 25: 275-280, 2013.

14. Crossley AWA and Mahajan RP: The intensity of postoperative shivering is unrelated to axillary temperature. Anaesthesia 49: 205-207, 1994.

15. Wang W, Li Y, Sun A, Yu H, Dong J and Xu H: Determination of the median effective dose (ED50) of bupivacaine and ropivacaine unilateral spinal anesthesia: Prospective, double blinded, randomized dose-response trial. Anaesthesist 66: 936-943, 2017.

16. Finster M and Wood M: The Apgar score has survived the test of time. Anesthesiology 102: 855-857, 2005.

17. Wilson E, David A, MacKenzie N and Grant IS: Sedation during spinal anaesthesia: Comparison of propofol and midazolam. Br J Anaesth 64: 48-52, 1990. 
18. Roy JD, Girard M and Drolet P: Intrathecal meperidine decreases shivering during cesarean delivery under spinal anesthesia. Anesth Analg 98: 230-234, 2004.

19. Sessler DI: Complications and treatment of mild hypothermia. Anesthesiology 95: 531-543, 2001.

20. Rajek A, Greif R and Sessler DI: Effects of epidural anesthesia on thermal sensation. Reg Anesth Pain Med 26: 527-531, 2001.

21. Giuliano KK and Hendricks J: Inadvertent perioperative hypothermia: Current nursing knowledge. AORN J 105: 453-463, 2017.

22. Zhou P, Ge S, Wang Y, Xiong W, Wang T and Xue Z: Novamin infusion: A new method to cure postoperative shivering with hypothermia. J Surg Res 188: 69-76, 2014.

23. Webb PJ, James FMIII and Wheeler AS: Shivering during epidura analgesia in women in labor. Anesthesiology 55: 706-707, 1981

24. Kranke P, Eberhart LH, Roewer N and Tramèr MR: Single-dose parenteral pharmacological interventions for the prevention of postoperative shivering: A quantitative systematic review of randomized controlled trials. Anesth Analg 99: 718-727, 2004.

25. Horn EP, Sessler DI, Standl T, Schroeder F, Bartz HJ, Beyer JC and Schulte am Esch J: Non-thermoregulatory shivering in patients recovering from isoflurane or desflurane anesthesia. Anesthesiology 89: 878-886, 1998.

26. Kim G, Kim MH, Lee SM, Choi SJ, Shin YH and Jeong HJ Effect of pre-warmed intravenous fluids on perioperative hypothermia and shivering after ambulatory surgery under monitored anesthesia care. J Anesth 28: 880-885, 2014.

27. Golembiewski J: Pharmacological management of perioperative shivering. J Perianesth Nurs 30: 357-359, 2015

28. Gozdemir M, Usta B, Demircioglu RI, Muslu B, Sert H and Karatas OF: Magnesium sulfate infusion prevents shivering during transurethral prostatectomy with spinal anesthesia: A randomized, double-blinded, controlled study. J Clin Anesth 22: 184-189, 2010.

29. Shukla U, Malhotra K and Prabhakar T: A comparative study of the effect of clonidine and tramadol on post-spinal anaesthesia shivering. Indian J Anaesth 55: 242-246, 2011.
30. Pawar MS, Suri N, Kaul N, Lad S and Khan RM: Hydrocortisone reduces postoperative shivering following day care knee arthroscopy. Can J Anaesth 58: 924-928, 2011.

31. Haque MF, Rashid MH, Rahaman MS and Islam MR: Comparison between tramadol hydrochloride \& nalbuphine hydrochloride in the treatment of per-operative shivering after spinal anaesthesia. Mymensingh Med J 20: 201-205, 2011.

32. Tauzin-Fin P, Maurette P, Vincon G, Hecquet D, Houdek MC and Bonnet F: Clinical and pharmacokinetic aspects of the combination of meperidine and prilocaine for spinal anaesthesia. Can J Anaesth 39: 655-660, 1992.

33. Domino EF, Chodoff P and Corssen G: Pharmacologic effects of CI-581, a new dissociative anesthetic, in man. Clin Pharmacol Ther 6: 279-291, 1965.

34. Aroni F, Iacovidou N, Dontas I, Pourzitaki C and Xanthos T: Pharmacological aspects and potential new clinical applications of ketamine: Reevaluation of an old drug. J Clin Pharmacol 49: 957-964, 2009.

35. Reza FM, Zahra F, Esmaeel F and Hossein A: Preemptive analgesic effect of ketamine in patients undergoing elective cesarean section. Clin J Pain 26: 223-226, 2010.

36. Wang X, Xie H and Wang G: Improved postoperative analgesia with coadministration of preoperative epidural ketamine and midazolam. J Clin Anesth 18: 563-569, 2006.

37. White PF, Way WL and Trevor AJ: Ketamine--its pharmacology and therapeutic uses. Anesthesiology 56: 119-136, 1982.

38. Shahriari A, Khooshideh M and Heidari MH: Prevention of nausea and vomiting in caesarean section under spinal anaesthesia with midazolam or metoclopramide? J Pak Med Assoc 59: 756-759, 2009.

39. SharmaDR and Thakur JR: Ketamine and shivering. Anaesthesia 45: 252-253, 1990.

40. Hu P, Harmon D and Frizelle H: Patient comfort during regional anesthesia. J Clin Anesth 19: 67-74, 2007. 